\title{
Progressive licensing needs progressive open debate
}

$\mathrm{T}$ he worldwide withdrawal of rofecoxib (Vioxx) marked the end of an era of relative consumer innocence. It demonstrated unequivocally that, unlike other consumer "goods," pharmaceutical products cannot be driven by profit. Rather, the driver must be a transparent, patient-centred regulatory system that ensures drugs are safe and efficacious before and after their release.

In the wake of the rofecoxib fiasco, Health Canada and regulatory agencies worldwide are revisiting how they approve and monitor drugs under the moniker of progressive licensing. ${ }^{1}$ The US Senate, prompted by a seminal review of drug safety by the Institute of Medicine, recently passed a bill to extensively enhance the US Food and Drug Administration's (FDA) power to evaluate drugs, including significantly more post-market monitoring.

Health Canada states that its version of progressive licensing includes developing a patient-centered focus, gathering and synthesizing evidence on drugs from development onward and improving post-marketing surveillance. ${ }^{2}$ Health Canada is now gathering information and drafting position papers for consultation.

At this point, progressive licensing appears to mean a major overhaul of legislation and regulations to enhance approval and post-market surveillance. It may also mean that the threshold for approval of selected new drugs is lower, but that in exchange the requirements to continuously evaluate drugs post-market are higher. On the plus side, this might improve timely access to new treatments, but on the minus side it could mean that dangerous drugs slip through the regulatory cracks. The trade-off is obvious enough, but is it necessary? And, more important, who decides?

At present, 2 voices dominate the change process: the pharmaceutical industry and Health Canada. These voices, albeit important, are not the only stakeholders; their focus is far too narrow and potentially self-serving. Canada's health professionals, experts and the public are nowhere in the picture.

We believe that to have meaningful reform, Health Canada and the government must be immune to the pervasive influence of lobbyists. This could be accomplished by inviting the Canadian Academies of Science (our version of the US National Academies of Science, which oversees the Institute of Medicine) or the Canadian Academy of Health Sciences (our version of the US Institute of Medicine) to strike a blue-ribbon panel to advise Parliament. Through an open and transparent $\approx$ process, representatives should be appointed from major Canadian stakeholder groups, including the public, as well as foreign regulators. Those perspectives have much to add to the 2-note symphony of industry and Health Canada.

The panel could begin by examining the current system to determine whether, for example, we might be better served by increased separation between the drug approval and post- market surveillance functions and by increased powers for appropriate drug monitoring. Currently, pre-market approval requires only 2 phase III trials in highly selected patients. These yield too few data in too few patients. As part of the approval process, the panel could insist that drugs undergo large pragmatic trials. Canada could also draw on its unique strength in the area of systematic reviews with the Cochrane Collaboration and evidence-based practice centers. These reviews can yield meaningful results, as demonstrated recently by the cardiac-risk warning attached to rosiglitazone (Avandia) by the US FDA. ${ }^{3}$ The panel should determine how best to integrate such expertise as it develops an early warning system.

In the interest of efficiency, the panel could also evaluate the benefits of integration among regulatory agencies in Canada, the United States and Europe. Such harmonization may yield uniform and widely accepted high standards, avoid needless duplication of work and increase trust and, perhaps eventually, lead to synergistic areas of expertise in either clinical content or research methods.

Overall, rofecoxib, and more recently tegarserod (Zelnorm), ${ }^{4}$ demonstrate the need for greater openness and transparency in the decision-making processes. Pharmaceutical companies must provide access to all information on drug safety in a timely and usable fashion, perhaps by posting major results in public trial registries. There must be greater cooperation among all levels of government so that all necessary information can be accessed by researchers and interested parties. For members of a future panel, there is much to consider.

We believe that Health Canada's progressive licensing, without progressive openness of debate, is not likely to be progress at all. The design of the drug regulatory framework is too important to be left to bureaucrats and industry alone. It must be yanked away and thrown open to a frank, broadminded discussion of society's needs.

Paul C. Hébert, Editor-in-Chief, $C M A J$ With the Editorial-Writing Team (Matthew Stanbrook, Barbara Sibbald, Ken Flegel, Noni MacDonald and Amir Attaran)

Competing interests: Noni MacDonald is a fellow of the Canadian Academy of Health Sciences. None declared by other members of the editorial-writing team.

\section{REFERENCES}

I. Kondro W. Health Canada proposes new regulatory regime for drugs. CMAJ 2007; I76:I26I-2.

2. Yeates N, Lee DK, Maher M. Health Canada's Progressive Licensing Framework. CMAJ 2007;176:1845-7.

3. Nissen SE, Wolski K. Effect of rosiglitazone on the risk of myocardial infarction and death from cardiovascular causes. N Engl J Med. Epub 2007 May 2I ahead of print. Available: http://content.nejm.org/cgi/content/full/NEJMoa07276I (accessed 2007 May 22)

4. Wright JM. Progressive drug licensing: An opportunity to achieve transparency and accountability? $C M A J$ 2007;176:1848-9. 